\title{
Le prix Nobel \\ de physique 2018
}

\section{En 2018, le Prix Nobel a récompensé deux découvertes qui ont révolutionné le monde des lasers}

et de leur utilisation. Il a été attribué pour moitié à Arthur Ashkin pour l'invention des pinces optiques et leurs applications aux systèmes biologiques, et pour moitié à Gérard Mourou et Donna Strickland pour la technique (dite CPA) permettant la génération d'impulsions laser ultra-courtes et ultra-intenses.

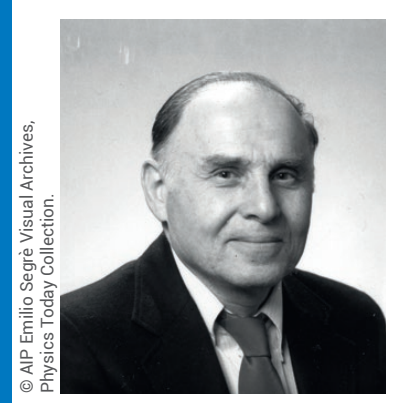

Arthur Ashkin est un physicien américain, né en 1922 à New-York. Il a effectué toute sa carrière au sein des Bell Labs et a pris sa retraite en 1992, sans pour autant cesser de poursuivre des recherches personnelles. Il fait ses études à l'université de Columbia et obtient en 1952 un PhD à l'université de Cornell. II intègre ensuite les Bell Labs dans le centre de Murray Hill et, à partir de 1967, il dirige le Département de recherches sur les sciences des lasers du centre d'Holmdel.

A. Ashkin est à l'origine de très nombreuses découvertes, auteur d'une cinquantaine de brevets et d'un grand nombre de " premières", mais c'est dans ses recherches sur les forces exercées par la lumière sur la matière qu'il établit sa plus grande renommée. En 1970, il découvre comment faire léviter une petite bille transparente avec un faisceau laser. Il s'intéresse ensuite à la manipulation des atomes et, en 1986, avec Steven Chu, prix Nobel 1997 partagé avec Claude Cohen-Tannoudji et William B. Phillips, il démontre expérimentalement pour la première fois le piégeage d'atomes dans des « mélasses » optiques. En 1987, il réussit le piégeage et la manipulation non destructive par laser d'objets biologiques tels que des virus et des bactéries. Il ouvre ainsi l'histoire de l'utilisation de « pinces » optiques pour l'étude des processus biologiques, et pose les bases d'approches nouvelles pour la compréhension des processus d'infection et des mécanismes internes de la cellule, ce pourquoi il est récompensé par ce Prix Nobel.

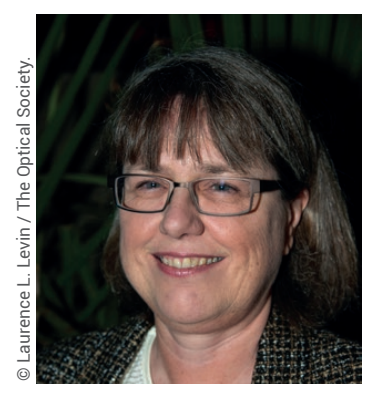

Donna Strickland est une physicienne canadienne, née en 1959 à Guelph dans l'Ontario. Elle est actuellement professeure à l'université de Waterloo (Canada).

Très tôt attirée par l'expérimentation et les lasers, elle obtient en 1981 un master en génie physique de I'université McMaster (Canada) puis, en 1989, un doctorat de l'université de Rochester (États-Unis). C'est avec ses travaux de thèse, effectués sous la direction de Gérard Mourou, que la technique du CPA a vu le jour. De 1988 à 1991, elle a ensuite travaillé au Conseil national de recherches du Canada avec Paul Corkum, puis successivement à Livermore et à Princeton.

Elle rejoint en 1997 I'université de Waterloo, où elle dirige un groupe de recherche sur les lasers ultrarapides. Elle est lauréate de plusieurs prix et membre fellow de l'American Optical Society (OSA), dont elle a été la présidente en 2013.

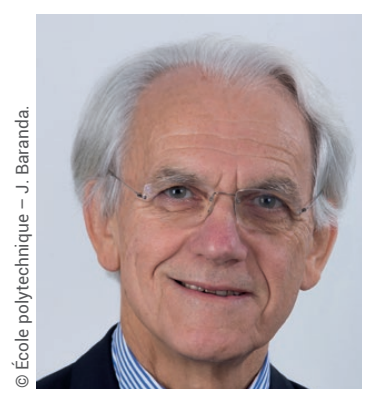

Gérard Mourou est un physicien français né en 1944 à Albertville. II est actuellement professeur et membre du Haut-collège de l'École polytechnique.

Dans les années 1970, son parcours se partage entre le Canada à l'université de Laval, les États-Unis à l'université de Californie à San Diego, et la France au Laboratoire d'optique appliquée à Palaiseau, laboratoire dont il prendra ensuite la direction de 2005 à 2008.

De 1977 à 1988, il dirige des recherches à l'université de Rochester sur les lasers à impulsions très courtes, et c'est là qu'il développe le concept du CPA et en fait la première démonstration avec Donna Strickland. De 1988 à 2005, il est professeur à l'université du Michigan où il fonde le Center for Ultrafast Optical Science (CUOS).

G. Mourou est auteur d'un très grand nombre de publications et de brevets. Il a obtenu de nombreuses distinctions parmi les plus prestigieuses. Sans être exhaustif, le dossier qui suit donne des compléments d'information sur l'impact majeur qu'ont eu ses recherches dans le monde des lasers et de leurs applications. 